\title{
Landscape Ecology of the Upper Mississippi River System: Lessons learned, challenges and opportunities
}

The Upper Mississippi River System (UMRS) is a mosaic of river channels, backwater lakes, floodplain forests, and emergent marshes. This complex mosaic supports diverse aquatic and terrestrial plant communities, over 150 fish species; 40 freshwater mussel species; 50 amphibian and reptile species; and over 360 bird species, many of which use the UMRS as a critical migratory route. The river and floodplain are also hotspots for biogeochemical activity as the river-floodplain collects and processes nutrients derived from the UMR basin. These features qualify the UMRS as a Ramsar wetland of international significance.

Two centuries of land-use change, including construction for navigation and conversion of large areas to agriculture, has altered the broad-scale structure of the river and changed local environmental conditions in many areas. Such changes have affected rates of nutrient processing and transport, as well as the abundance of various fish, mussel, plant, and bird species. However, the magnitude and spatial scale of these effects are not well quantified, especially in regards to the best methods and locations for restoring various aspects of the river ecosystem.

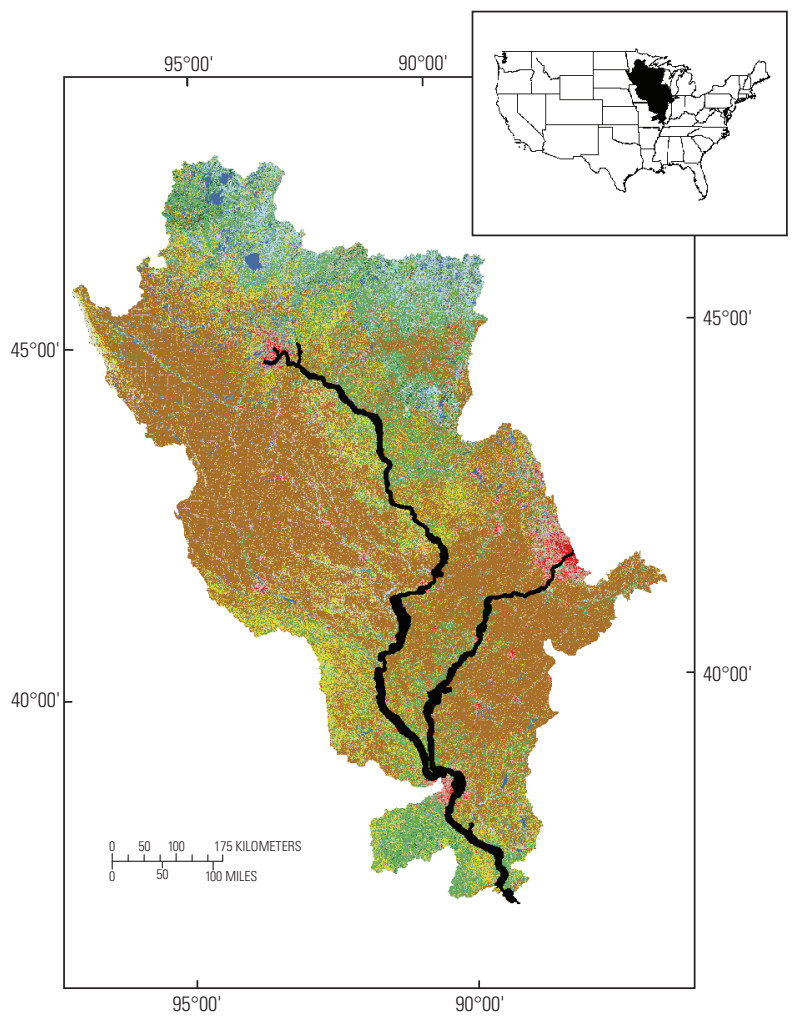

The U.S. Congress declared the navigable portions of the Upper Mississippi River System (UMRS) (shown here flowing through the UMR basin) a "nationally significant ecosystem and nationally significant commercial navigation system" in the Water Resources Development Act of 1986 (Public Law 99-662) and launched the Upper Mississippi River Restoration (UMRR) Program, the first comprehensive program for ecosystem restoration, monitoring, and research on a large river system. This fact sheet focuses on landscape ecological studies conducted by the U.S. Geological Survey to support decision making by the UMRR with respect to ecosystem restoration.
Today's distribution of water (translucent blue) within the river-floodplain when compared with historical river conditions (background images) shows areas that have been affected by navigation dams in the northern UMR (left panel) and areas in the lower UMR that have been channelized (right panel). In each situation, the conditions within, as well as the diversity of and connectivity among, major floodplain and aquatic habitats have been altered.
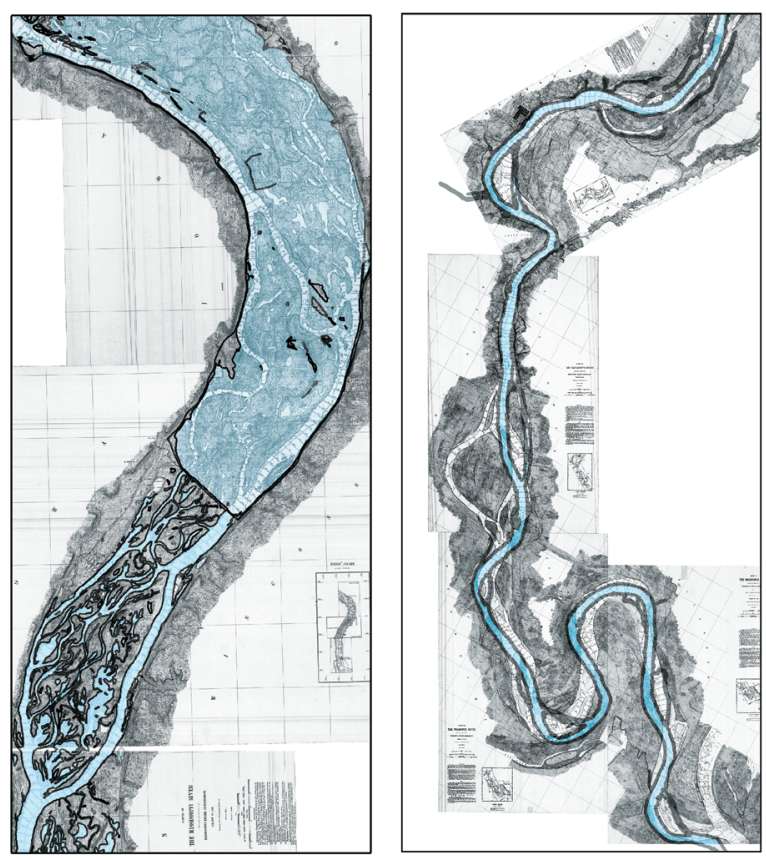


\section{Landscape Ecology on the UMRS}

Landscape ecological research on the UMRS addresses resource management questions. At the broadest scale, maps and measures of various land-cover types, vegetation communities, and aquatic areas are used to help managers make more informed decisions regarding locations for habitat restoration across the entire UMRS. Furthermore, by linking local ecological properties (for example, species occurrences or concentrations of limiting nutrients) with landscape patterns of major structuring processes (for example, water current velocity or annual flooding durations), the specific ecological conditions needed to achieve various restoration objectives can be better identified.

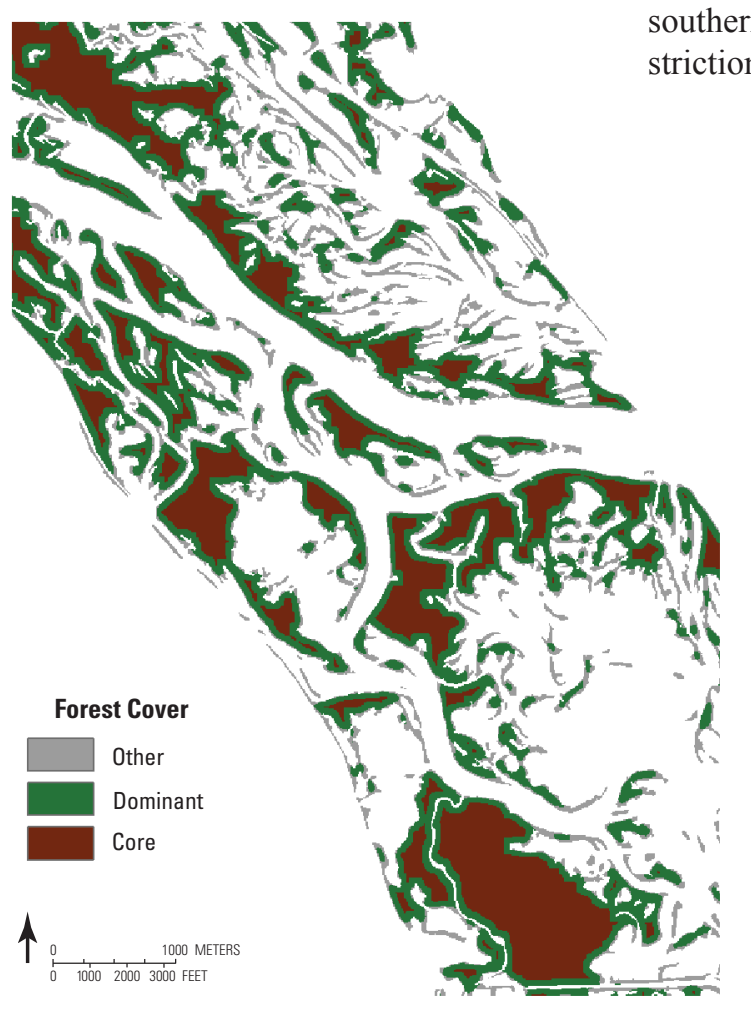

\section{Landscape Indicators}

Measures that characterize the spatial arrangement of various landcover types, vegetation communities, or aquatic areas (that is, landscape indicators) can provide a large-scale context for understanding potential constraints on local ecological conditions. For example, multivariate analyses were used to examine land-cover change in the UMRS floodplain from about 1890 to 2000 and to predict conditions in 2050 (De Jager and others, 2011). That study confirmed that most historical changes in land cover consisted of the expansion of open water and loss of floodplain forest, backwater lakes and side channels in the northern UMRS following dam construction and the expansion of agricultural land and loss of forests and side channels in the southern UMRS following channel contriction and levee construction.
Current and future land-cover changes were most sensitive to variation in regional climatic conditions, which drive changes in river hydrology and produce shifts in the distribution of land cover, vegetation types, and aquatic areas. These findings underscore the importance of regional drivers of river structure and potential changes in the UMRS that might arise as a result of climate change.

Against this backdrop of historical and possible future changes in the land cover of the UMRS, managers are faced with the challenge of identifying specific locations for restoration of floodplain forests, backwater lakes, islands, and side channels. Therefore, recent studies have developed maps and metrics of floodplain forest fragmentation (De Jager and Rohweder, 2011a) and aquatic area diversity (De Jager and Rohweder, 2011b). Spatial variation in metric scores reflect historical effects of navigation infrastructure, agriculture, and urban development, and can be used to assess differences between areas of the floodplain, therefore, helping to set regional priorities for restoration.
Maps of forest cover and fragmentation (left) help managers identify areas that could benefit from the restoration of forest cover. Metric scores can be derived from maps and used to identify areas for restoration across the entire UMR. For example, shown below is the rate of increase in aquatic area diversity with increasing spatial scale (ha,z) along the length of the UMR, starting at the confluence with the Ohio River (0), the horizontal line denotes the river-wide mean.

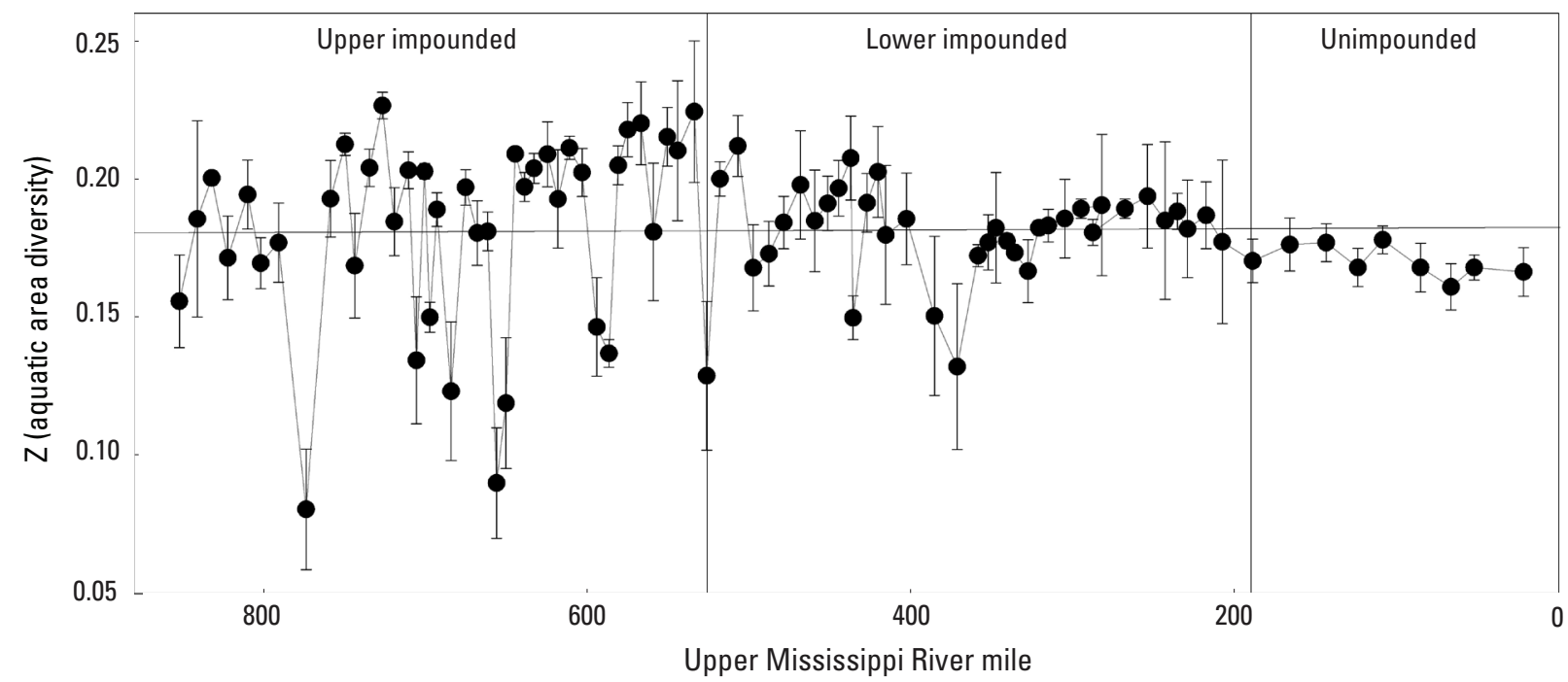




\section{Ecological Relationships}

Spatial patterns of ecological properties can be used to identify the types of broad-scale patterns needed to support specific ecological functions or species. For example, spatial patterns of nitrogen $(\mathrm{N})$ and phosphorous $(\mathrm{P})$ in the UMRS reflect fundamental river processes and often underpin the production and composition of aquatic plant and animal communities. In a recent study, patch distributions of $\mathrm{N}$ and $\mathrm{P}$ were strongly tied to the distribution of backwater areas in the UMRS, and nutrient concentrations within patches were associated with current velocity (DeJager and Houser, 2012). This information can be used by managers to identify the types of aquatic areas and local characteristics (for example, current velocity and connectivity to channels) that may produce different rates of nutrient delivery and cycling.

Another recent study examined relations between spatial variation in floodplain forest and soil properties and landscape patterns of flood duration in the upper impounded reach (De Jager and others, 2012). Tree species with low flood tolerances and soils with high sand content were generally found in high elevation areas that typically flood for less than 40 days of the growing season. Quantifying these relations helps managers understand the potential soil nutrient dynamics in various parts of the floodplain and more accurately account for tree species recruitment patterns in relation to topographical variation when designing forest restoration projects.

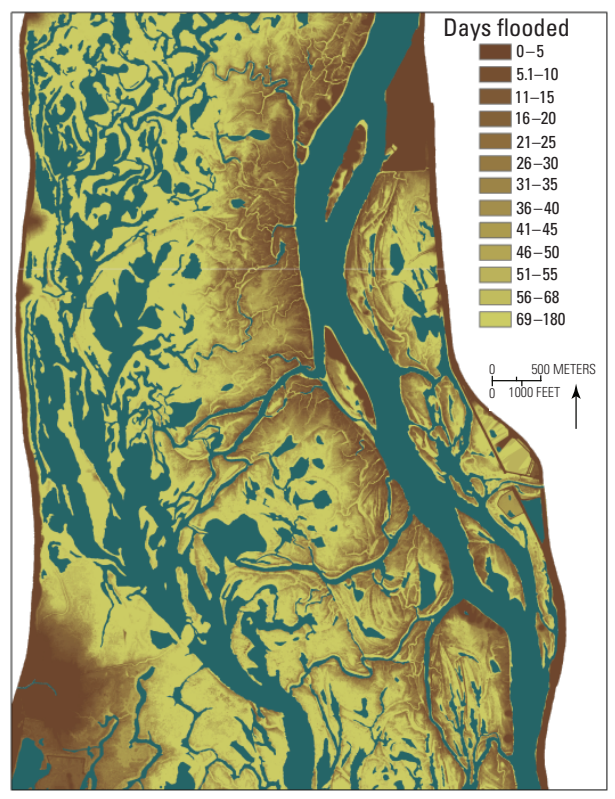

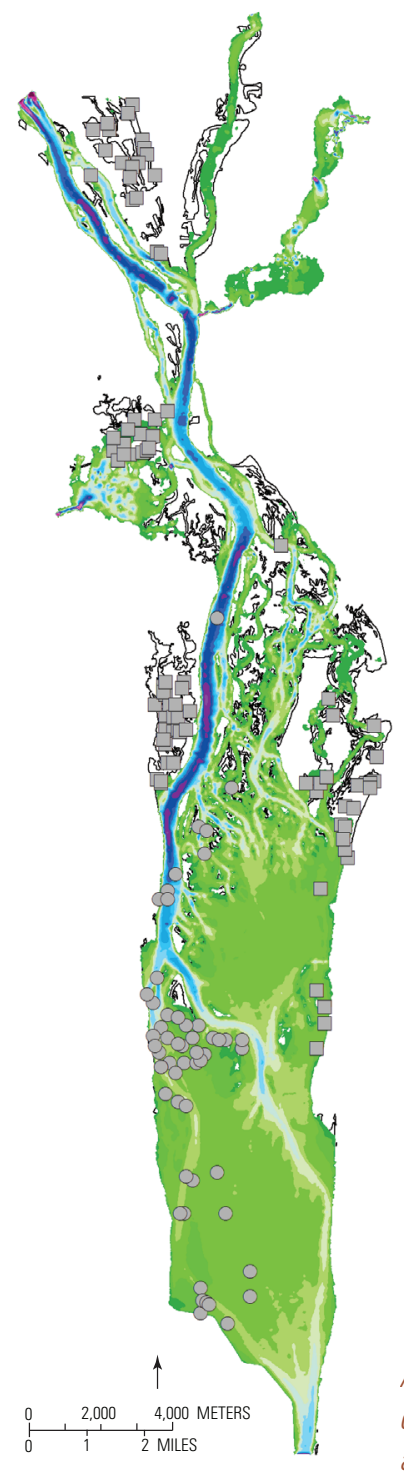

\section{Flow velocity} $-(\mathrm{cm} / \mathrm{sec})$

\begin{tabular}{|l}
\hline \\
\hline \\
$0-2$ \\
$2-5$ \\
$5-10$ \\
$10-15$ \\
$15-20$ \\
\hline $20-25$ \\
$25-30$ \\
$30-35$ \\
$35-40$ \\
$40-45$ \\
$45-50$ \\
$50-60$ \\
$60-70$ \\
$70-80$ \\
$80-90$ \\
$90-100$ \\
$100-150$ \\
$150-200$ \\
$>200$ \\
\hline
\end{tabular}

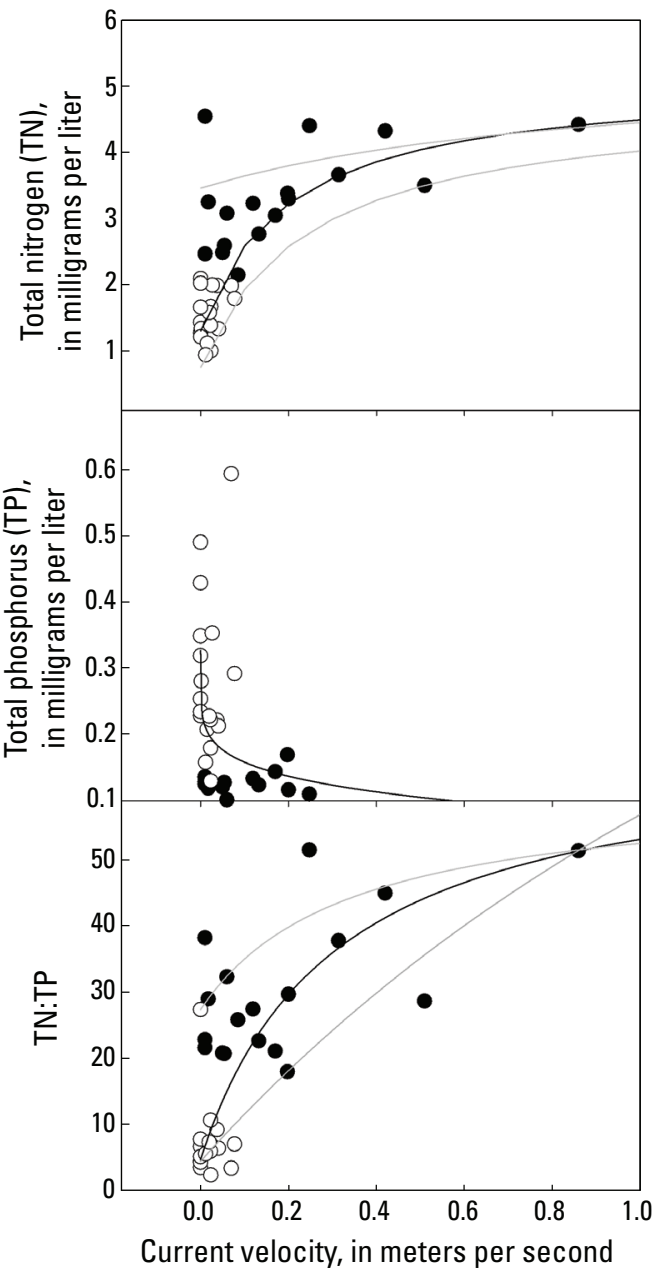

A map of areas that constitute patches of high (circles) and low (squares) concentrations of total nitrogen (TN), overlaid upon a map of current velocity for an average summer day in Pool 8 of the UMR. The graphs to the right show associations between current velocity and concentrations of TN and total phosphorus (TP) within patches of high (filled circles) and low (open circles) TN:TP ratios.
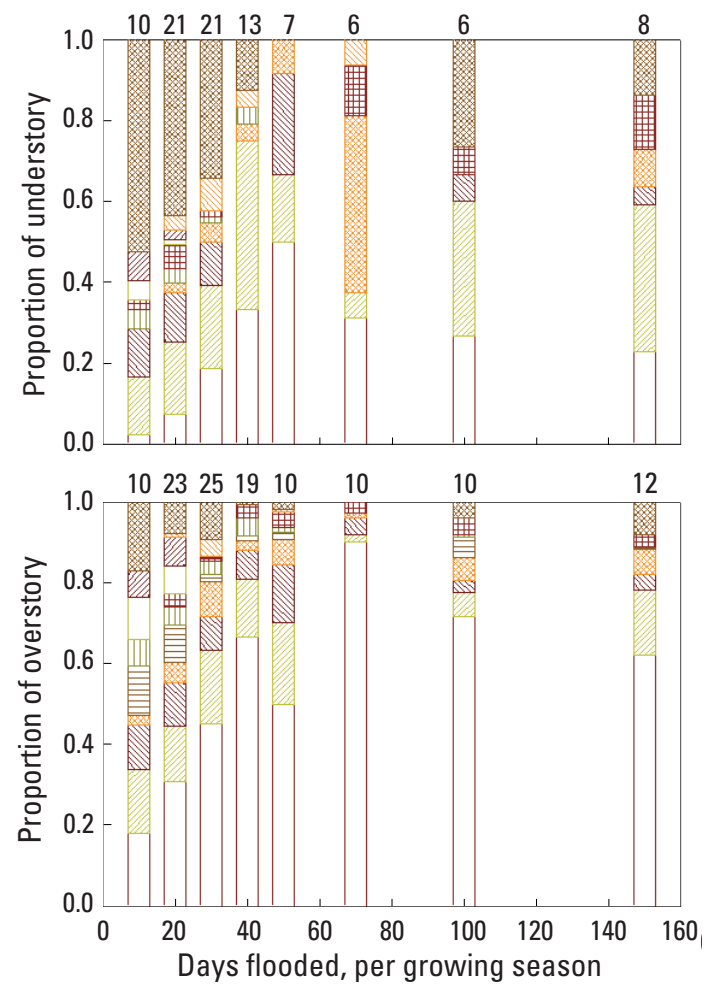

Tree species

$$
\begin{array}{ll}
\text { Other } \\
\text { Northern Red Oak } \\
\text { Black Locust } \\
\text { Swamp White Oak } \\
\text { Boxelder } \\
\text { Gastern Cottonwood } \\
\text { Giver Birch } \\
\text { Silver Ash } \\
\hline \text { Saple }
\end{array}
$$

Landscape distributions of flood duration (left panel) and associated patterns of understory and overstory tree species composition (right panels). Note the strong increase in the proportion of silver maple (ACSA2) in the overstory with increasing flood duration from 10 to 40 growing season days. Numbers on the top of graphs indicate sample sizes. 


\section{Challenges and Opportunities:}

Landscape pattern research on the UMRS is generating information about the spatial arrangement of various land cover and habitat types; information that could be used to identify areas for restoration across the entire UMRS. Such regional-scale approaches to restoration are challenging to implement because of complex patterns of floodplain land ownership and the desire to balance ecological, economic and navigation needs. However, a strong partnership exists among the five states that border the UMRS (Illinois, Iowa, Minnesota, Missouri, and Wisconsin), providing an outstanding opportunity to develop a regional scale approach to restoration project identification and sequencing.

Landscape pattern research is also developing information about the types of landscape patterns that are likely to produce local changes in ecological conditions. However, predicting the likely effects of restoration or management actions is challenging because short-term environmental conditions immediately following a restoration project (e.g. unpredictable flooding or drought) can modify ecological responses. Furthermore, species interactions are often unpredictable (e.g., presence of invasive species) and can further modify an expected response to habitat restoration.
These challenges can only be addressed by coupling ecological studies with real restoration actions. This constitutes an opportunity to link the modification of landscape patterns, via management actions, with studies that examine local to regional-scale ecological responses to those actions.

\section{For more information:}

\section{Contact:}

Nathan De Jager, USGS,

Landscape Ecologist,

ndejager@usgs.gov / 608-781-6232

\section{Visit:}

http://www.mvr.usace.army.mil/Missions/ EnvironmentalProtectionandRestoration/ UpperMississippiRiverRestoration.aspx

to find out more about the Upper Mississippi River Restoration Program, a partnership among the U.S. Army Corps of Engineers, U.S. Geological Survey, U.S. Fish and Wildlife Service, and the five states that border the UMRS: Illinois, Iowa, Minnesota, Missouri, and Wisconsin.

\section{Visit:}

http://www.umesc.usgs.gov/ltrmp.html

to find out more about the Long Term Resource Monitoring element of UMRR.

\section{Literature Cited}

De Jager, N.R., Rohweder, J.J., and Nelson, J.C., 2011, Past and predicted future changes in the land cover of the Upper Mississippi River floodplain, USA: River Research and Applications. 10.1002/rra.1615

De Jager, N.R., and Rohweder, J.J., 2011a, Spatial scaling of core and dominant forest cover in the Upper Mississippi and Illinois River floodplains, USA: Landscape Ecology, v. 26, p. 697-708.

De Jager, N.R., and Rohweder, J.J., 2011b, Spatial patterns of aquatic habitat richness in the Upper Mississippi River floodplain, USA: Ecological Indicators, v. 13 , p. 275-283.

De Jager, N.R., and Houser, J.N., 2012, Variation in water mediated connectivity influences patch distributions of total nitrogen (TN), total phosphorous (TP) and TN:TP ratios in the Upper Mississippi River, USA: Freshwater Science, v. 31 , p. 1254-1272.

De Jager, N.R., Thomsen, M.T., and Yin, Y., 2012, Threshold effects of flood duration on the vegetation and soils of the Upper Mississippi River floodplain, USA: Forest Ecology and Management, v. 270 , p. $135-146$.

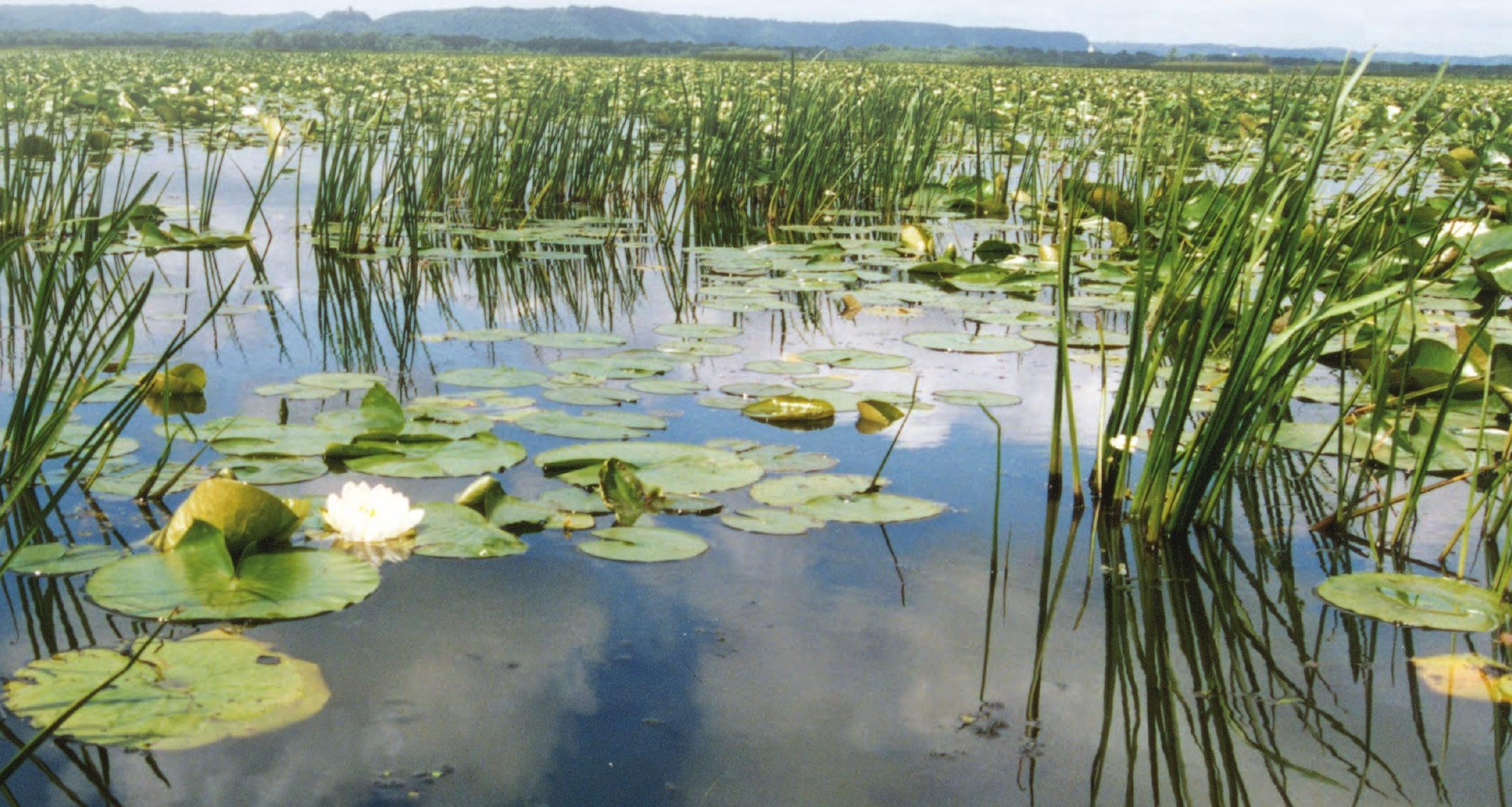

